\title{
IDENTIFIKASI SINYAL ELEKTRO ENSEPHALO GRAPH SEBAGAI PENGGERAK KURSOR DENGAN DISCRETE FOURIER TRANSFROM DAN K-NEAREST NEIGHBORS
}

\author{
Tarekh Alif Firmasnyah" ${ }^{1}$, Hindarto ${ }^{2}$ \\ 1, 2, Program Studi Informatika, Fakultas Sains dan Teknologi, Universitas Muhammadiyah Sidoarjo \\ ${ }^{1} 151080200194 @ u m s i d a . a c . i d,{ }^{2}$ hindarto@umsida.ac.id
}

\begin{abstract}
Abstrak
Penelitian ini menjelaskan aplikasi tetangga terdekat $\mathrm{k}$ yang mengeksekusi klasifikasi sinyal EEG dan menyajikan konsep metode Discrete Fourier Transfrom (DFT) untuk ekstraksi fitur dari sinyal electroencephalogram (EEG). Data yang digunakan adalah data yang mengatur subjek untuk mengontrol kursor yang bergerak di monitor dengan membayangkan gerakan tangan kanan dan tangan kiri yang diambil dari BCI Competition 2005. Data ini berisi data dari subjek, dari merekam gerakan imajinasi tangan kiri (kelas 1) dan tangan kanan (kelas 2). Pengambilan keputusan dilakukan dalam dua tahap. Pada tahap pertama, metode DFT digunakan untuk ekstraksi fitur, sedangkan pada tahap ini nilai deviasi minimum, maksimum, median, dan standar deviasi akan diambil. Fitur ini adalah input dasar untuk tetangga k-terdekat sebagai proses klasifikasi. Dalam proses klasifikasi, nilai akurasi untuk setiap tetangga akan digunakan untuk menarik kesimpulan. Hasil yang diperoleh untuk prediksi klasifikasi sinyal paling baik sebesar $65 \%$ untuk titik $\mathrm{K}=5$.
\end{abstract}

Kata Kunci: Discrete Fourier Transform (DFT), Electro Encephalo Graph (EEG), K-Nearest Neighbours $(\mathrm{KNN})$

\section{Pendahuluan}

Otak sebagai struktur inti pusat kendali aktivitas tubuh manusia, berperan aktif dan bertanggung jawab atas seluruh kendali aktivitas tubuh manusia. EEG atau Electro Encephalo Graph adalah sinyal yang di keluarkan otak manusia ketika menerima informasi yang masuk dari beberapa neuron [1]. Bentuk sinyal EEG pada setiap manusia berbeda-beda tergantung dari kapasitas otak dan respon rangsangan yang di terima otak dari informasi yang masuk [2].

Brain Computer Interface atau disingkat $B C I$ ialah sebuah teknologi yang memanfaatkan sinyal otak untuk mengendalikan sesuatu dalam arti lain sebuah teknologi yang tidak menggunakan kegiatan otot. Secara umum konsep BCI sebagai masukan sistem, komputer sebagai pengelolah dan penerjemah pola dan sinyal memerintah ke alat tertentu sebagai keluaran sistem. Konsep ini dapat di jalankan di sistem apapun asalkan sistem mampu mengenali pola dari gelombang otak yang di keluarkan sesuai kebutuhan sistem [3].

Pemanfaatan Electro Encephalo Graph (EEG) dan Brain Computer Interface (BCI) sangat berkesinambungan, $E E G$ sebagai sistem pembaca sinyal neuron yang di keluarkan oleh otak seorang individu untuk mengerjakan aktivitas di tangkap, di terjemahkan, dan di implementasikan ke salah satu perangkat tertentu oleh BCI[4]. Dalam hal ini peneliti ingin mengimplementasikan system sinyal
EEG dan BCI untuk mengolah sinyal otak manusia menjadi sistem dan alat untuk menggerakkan kursor dan menjadi pengganti perangkat keras (mouse) [5].

Dalam penelitian yang akan diteliti, peneliti akan merancang untuk melakukan klasifikasi pergerakan kursor didasarkan pada pemikiran otak setiap individu manusia menggunakan sinyal EEG dengan mengambil kosep dari Brain Computer Interface atau BCI mengambil data dari BCI Competition pada tahun 2003 dengan menggunakan data set IIIA subjek 2 Channel A dan menggunakan metode DFT dan algoritma K-NN[6].

\section{Metodologi penelitian \\ 2.1 Analisis Kebutuhan}

Pada kesempatan ini penulis akan mengidentifikasi sinyal Elektro Enshephalo Graph (EEG). Untuk memudahkan identifikasi dan mendapatkan hasil yang akurat, maka akan digunakan sistem pengolahan sinyal. Sistem akan dibuat dengan bahasa pemrograman MATLAB 2013a sebagai perangkat lunak yang dapat membantu menyelesaikan permasalahan identifikasi kualitas Elektro Ensephalo Graph (EEG). Identifikasi akan dilakukan dengan metode Discrete Fourier Trasfrom (DFT). 


\subsection{Hasil Analisa}

Berdasarkan analisa diatas maka dapat digunakan sistem pengolahan citra yang mampu mengidentifikasi sinyal Elektro Enshepalo Graph (EEG) menggunakan K-Nearest Neighbor (KNN). Tahapan pada sistem tersebut diantaranya input data, preprocessing, ekstraksi fitur dan klasifikasi data.

\subsubsection{Kebutuhan Fungsional}

1. Kebutuhan Perangkat Keras (Hardware)

Perangkat keras yang dibutuhkan untuk mengidentifikasi kualitas bawang merah sebagai berikut:
a. Laptop Asus
b. Processor: Intel®Core i5 - 5200U CPU $2.7 \mathrm{GHz}$.
c. Memori RAM : 4,00 GB
d. Hardisk : 5,00 GB

2. Kebutuhan Perangkat Lunak (Software)

Perangkat lunak yang digunakan dengan spesifikasi sebagai berikut:
a. Bahasa pemrograman: Matlab R2013a
b. Operating System : Windows 10 Pro

3. Lokasi Pengambilan Data

Lokasi penelitian dilakukan di Laboratorium Informatika Kampus 2 Universitas Muhammadiyah Sidoarjo.

\subsubsection{Akuisisi Data}

Pengambilan data dari BCI Competition 2005 hasil perekaman terdiri dari 60 channel dan 986780 data $(986780 \times 60)$ dan dari data tersebut dibagi menjadi beberapa kelas untuk contohnya penulis mengambil salah satu channel yaitu channel A dimana 986780 (data rekam) : 360 (data class) $=$ menghasilkan 2.741,055 data. Dengan kata lain pada setiap pencitraan dilakukan maka menghasilkan 2.741 data perekaman pada masingmasing kelas. Setelah itu dari data itu di jadikan grafik sinyal.

\subsubsection{Preprocessing}

Dari data set yang terdiri dari 60 channel dan 986780 data sinyal kemudian dari 1 channel yang di pilih kemudian dari 986780 (data rekam) : 360 (data class(180 data untuk kelas 1,2,3,4 dan 180 data untuk NaN)) = menghasilkan 2.741,055 data. Dengan kata lain pada setiap pencitraan dilakukan maka menghasilkan 2.741 data perekaman pada masing-masing kelas. Dari proses tersebut kemudian di sorting menurut kelas yang ada.

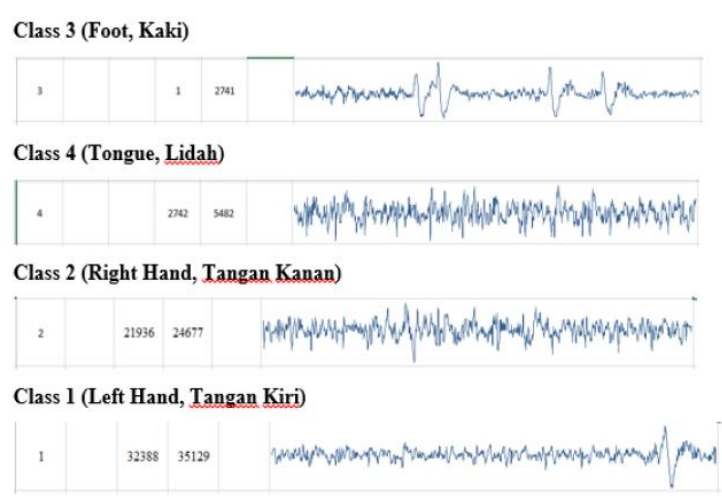

Gambar 1. Tampilan sinyal per kelas

\subsection{Flowchart Sistem}

Proses sistem dimulai dengan memasukkan sinyal EEG, kemudian data yang diperoleh akan memasuki proses ekstraksi fitur. Setelah proses ekstraksi, data akan diproses dalam proses klasifikasi menggunakan k-tetangga terdekat dan nilai akurasi akan dicari.

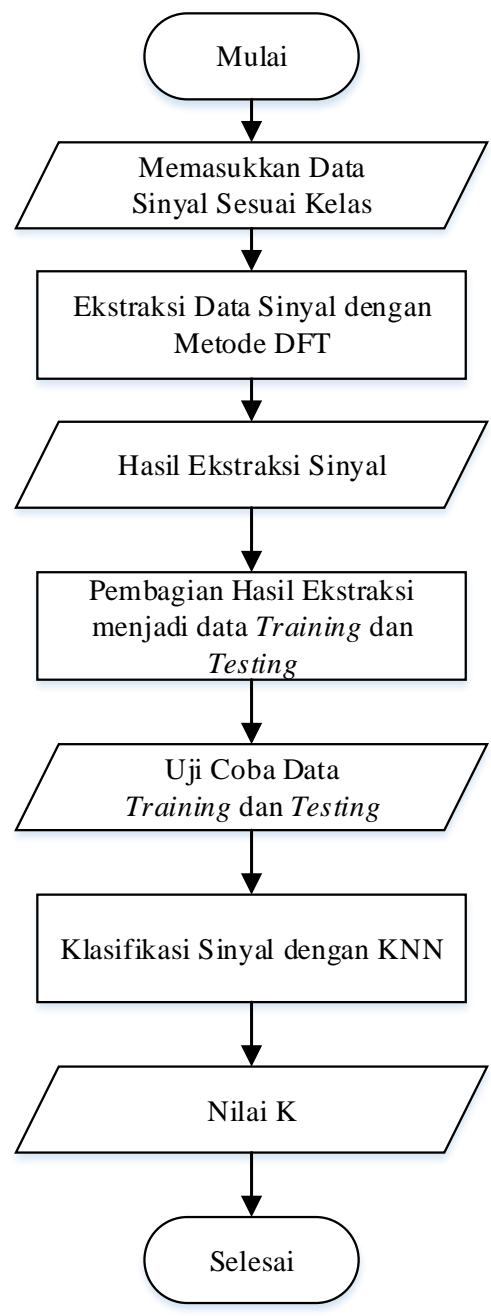

Gambar 2. Flowchart Sistem 


\subsection{User Interface}

Berikut ini adalah tampilan rancangan user interface:

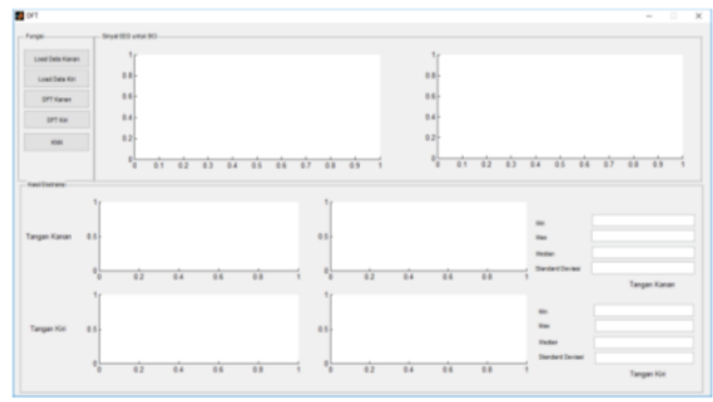

Gambar 3. Tampilan Utama

\section{Hasil}

\subsection{Hasil Esktraksi Fitur}

Ekstraksi Ciri dengan Metode Discrete Fourier Transfrom. Dari 2 kelas sinyal EEG yang telah dipilih yaitu kelas tangan kanan dan kiri yang mempunyai 45 percobaan dan 2741 panjang sinyal pada masing-masing percobaan kemudian di ektraksi menjadi 90 nilai dan di dicari nilai minimum, maksimum, median dan standar deviasi pada masing-masing nilai percobaan. Nilai tersebut sebagai input untuk klasifikasi menggunakan tetangga $k$-nearest.

\begin{tabular}{|c|c|c|c|c|c|}
\hline \multicolumn{6}{|c|}{ Hasil Ekstrasi DFT } \\
\hline No & MIN & MAX & MEDIAN & $\begin{array}{c}\text { STANDAR } \\
\text { T } \\
\text { DEVIASI }\end{array}$ & KELAS \\
\hline Percobaan 1 & 5.87E-01 & $-2.50 \mathrm{E}+03$ & $1.96 \mathrm{E}+01$ & $3.61 \mathrm{E}+02$ & 1 \\
\hline Percobaan 2 & $-3.02 \mathrm{E}-01$ & $-1.93 E+03$ & $-2.19 \mathrm{E}+01$ & $5.30 \mathrm{E}+02$ & 1 \\
\hline Percobaan 3 & 1.79E-01 & $-2.22 E+03$ & $-2.47 \mathrm{E}+01$ & $3.62 \mathrm{E}+02$ & 1 \\
\hline Percobaan 4 & $-3.39 \mathrm{E}-01$ & $-2.63 \mathrm{E}+03$ & $8.21 \mathrm{E}+00$ & $3.81 \mathrm{E}+02$ & 1 \\
\hline Percobaan 5 & $8.18 \mathrm{E}-01$ & $1.36 \mathrm{E}+03$ & $1.98 \mathrm{E}+01$ & $5.31 \mathrm{E}+02$ & 1 \\
\hline Percobaan 6 & $-3.09 \mathrm{E}-01$ & $-1.22 \mathrm{E}+02$ & $1.64 \mathrm{E}+01$ & $3.46 \mathrm{E}+02$ & 1 \\
\hline Percobaan 7 & $7.39 \mathrm{E}-01$ & $5.49 \mathrm{E}+02$ & $2.40 \mathrm{E}+01$ & $5.03 \mathrm{E}+02$ & 1 \\
\hline Percobaan 8 & $1.26 \mathrm{E}-02$ & $3.86 \mathrm{E}+03$ & $-2.79 \mathrm{E}+01$ & $4.31 \mathrm{E}+02$ & 1 \\
\hline Percobaan 9 & $-8.70 \mathrm{E}-01$ & $5.73 \mathrm{E}+02$ & $1.63 \mathrm{E}+01$ & $5.28 \mathrm{E}+02$ & 1 \\
\hline Percobaan 10 & $1.48 \mathrm{E}-02$ & $3.16 \mathrm{E}+03$ & $3.50 \mathrm{E}+00$ & $4.52 \mathrm{E}+02$ & 1 \\
\hline \multicolumn{6}{|c|}{ 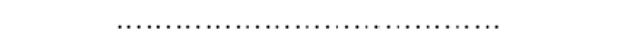 } \\
\hline Percobaan 82 & $2.28 \mathrm{E}-01$ & $1.12 \mathrm{E}+03$ & $-1.56 \mathrm{E}+01$ & $3.74 \mathrm{E}+02$ & 2 \\
\hline Percobaan 83 & $8.17 \mathrm{E}-02$ & $-5.65 \mathrm{E}+02$ & $2.53 \mathrm{E}-01$ & $4.51 \mathrm{E}+02$ & 2 \\
\hline Percobaan 84 & $1.80 \mathrm{E}-01$ & $-2.24 E+03$ & $1.62 \mathrm{E}+01$ & $3.26 \mathrm{E}+02$ & 2 \\
\hline Percobaan 85 & $3.54 \mathrm{E}-01$ & $-3.74 E+03$ & $4.20 \mathrm{E}+00$ & $4.69 \mathrm{E}+02$ & 2 \\
\hline Percobaan 86 & $-1.56 \mathrm{E}-01$ & $-6.50 \mathrm{E}+03$ & $-2.66 \mathrm{E}+01$ & $6.34 \mathrm{E}+02$ & 2 \\
\hline Percobann 87 & $5.11 \mathrm{E}-02$ & $9.68 \mathrm{E}+02$ & $1.41 \mathrm{E}+01$ & $3.93 \mathrm{E}+02$ & 2 \\
\hline Percobaan 88 & $8.75 \mathrm{E}-02$ & $-2.82 E+03$ & 3.32E-01 & $3.87 \mathrm{E}+02$ & 2 \\
\hline Percobaan 89 & 2.65E-01 & $1.43 \mathrm{E}+03$ & $-1.72 \mathrm{E}+01$ & $3.69 \mathrm{E}+02$ & 2 \\
\hline Percobaan 90 & 2.14E-01 & $1.77 \mathrm{E}+03$ & $8.60 \mathrm{E}+00$ & $3.49 \mathrm{E}+02$ & 2 \\
\hline
\end{tabular}

Gambar 4. Hasil Ektrasi DFT

\subsection{Klasifikasi Data dengan $K$-Nearest Neighbour}

Dari 90 data ektrasi fitur dibagi menjadi $80 \%$ untuk Training dan 20\% untuk Testing. Pada tahap klasifikasi akan ada nilai akurasi dari beberapa tetangga yang berbeda. Dalam Gambar 6 menunjukkan hasil akurasi klasifikasi tetangga kterdekat dengan k-tetangga yang berbeda.

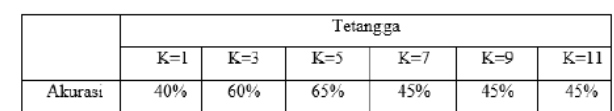

Gambar 6. Klasifikasi KNN dengan tetangga berbeda

Bentuk tes akurasi ini diperoleh dari ujicoba antara data Testing terhadap data Training dengan hasil prediksi K-NN, kemudian dihitung seberapa banyak data yang benar diprediksi oleh algoritma KNN. Berdasarkan hasil uji keakuratan diketahui bahwa $\mathrm{k}=5$ menghasilkan keakuratan $65 \%$. Akurasi K-tetangga tersebut lebik baik dari Ktetangga lain. Hasil akurasi berbeda dari jumlah ktetangga yang berbeda karena setiap perhitungan klasifikasi K-NN dengan k-tetangga yang berbeda memiliki hasil yang berbeda pula. Akurasi yang diperoleh dihitung dari jumlah klasifikasi benar atau (kelas benar) dibagi dengan jumlah semua data uji dan dikalikan dengan 100\%, menghasilkan akurasi perhitungan K-NN.

\section{Kesimpulan}

Dari hasil penelitian yang telah dilakukan, para peneliti memperkenalkan metode DFT untuk mengekstraksi fitur dan proses mengklasifikasikan sinyal EEG dengan Algotirhma KNN. Proses ekstraksi fitur dilakukan untuk menghasilkan karakteristik sinyal. nilai maksimum, minimum, median, dan standar deviasi akan ditentukan. Dari nilai ekstrasi tersebut akan di klasifikasikan menurut K-tetangga dan di cari akurasi. Akurasi klasifikasi dengan metode k-nn yang paling baik adalah $\mathrm{K}=5$ yaitu $65 \%$.

\section{Daftar Pustaka:}

Hindarto. (2014): Identifikasi Sinyal Elektro Enchepalo Graph Untuk Menggerakkan Kursor Menggunakan Regresi Parabolik dan K-Nearest Neigbor. Simposium Nasional Teknologi Terapan.

Karmila, R., Djamal, E. C., \& Nursantika, D. (2016): Identifikasi Tingkat Konsentrasi Dari Sinyal EEG Dengan Wafelet dan Adaptive Backpropagation. Seminar Nasional Aplikasi Teknologi Informasi.

landasan teori 2.1 sinyal . (2012). Retrieved from library.binus.ac.id:

http://library.binus.ac.id/eColls/eThesisdoc/ Bab2/2012-1-00552-mtif\%202.pdf

Lotte, F., \& Roy, R. N. (2019): Brain-Computer Interface Contributions to Neuroergonomics. Elsevier.

Nardiana, A., \& Sumaryono, S. (2011): Adaptive Noise Canceling Menggunakan Algoritma 
Least Mean Square (LMS). Jurnal Teknik Eklektro Vol 3 No. 1.

Pengantar Statistika. (2014). Retrieved from sdm.data.kemendikbud.go.id:

http://sdm.data.kemdikbud.go.id/upload/files /Pengantar\%20Statistik.pdf

Rachmawati, D., N.R, U. C., \& Riyananto, S. (2017): Classify Epilepsy and Normal Electroencephalogram (EEG) Signal Using Wavelet Transfrom and K-Nearest Neigbor. 3rd International Conference Science in Information Technology , 110.

Risky, A. (2019): Discrete Fourier Transfrom. Retrieved from academia.edu: academia.edu/23022372/Discrete_Fourier_T ransfrom

Satapahy, S. K., Dehuri, S., \& Jagadev, A. K. (2017): ABC optimized RBF network for classification of EEG signal for epileptic seizure identification. Egyption Informatics Journal.

www.sistem-informasi.xyz. (2017, february 03): Pengertian Sinyal Analog dan Sinyal Digital. Retrieved from pengertian-sinyal-analogdan-digital: http://www.sisteminformasi.xyz/2017/02/pengertian-sinyalanalog-dan-digital.html 